\title{
Article \\ A Decision Support System for Sustainable Agriculture: The Case Study of Coconut Oil Extraction Process
}

\author{
Gianfranco Gagliardi ${ }^{1, * \mathbb{D}}$, Antonio Igor Maria Cosma $^{2}$ and Francesco Marasco ${ }^{3}$ \\ 1 Dipartimento di Ingegneria Informatica, Modellistica, Elettronica e Sistemistica (DIMES), \\ Università della Calabria, Via P. Bucci, Cubo 42/c, 87036 Rende, CS, Italy \\ 2 WeSmart S.r.l., Via A. Monaco, 20, 87100 Cosenza, CS, Italy; a.cosma@wesmart.it \\ 3 Leão São Tomé and Principe Company, Rua 3 de Fevereiro, São Tomé 87220-000, Sao Tome and Principe; \\ mg.engineering.lda@gmail.com \\ * Correspondence: g.gagliardi@dimes.unical.it
}

Citation: Gagliardi, G.; Cosma, A.I.M.; Marasco, F. A Decision Support System for Sustainable Agriculture: The Case Study of Coconut Oil Extraction Process. Agronomy 2022, 12, 177. https:// doi.org/10.3390/agronomy12010177 Academic Editors: Giacomo Falcone, Antonio Violi and Thomas Bournaris

Received: 29 October 2021

Accepted: 9 January 2022

Published: 12 January 2022

Publisher's Note: MDPI stays neutral with regard to jurisdictional claims in published maps and institutional affiliations.

Copyright: (C) 2022 by the authors. Licensee MDPI, Basel, Switzerland. This article is an open access article distributed under the terms and conditions of the Creative Commons Attribution (CC BY) license (https:// creativecommons.org/licenses/by/ $4.0 /)$.

\begin{abstract}
The high demand of information and communication technology (ICT) in agriculture applications has led to the introduction of the concept of smart farming. In this respect, moving from the main features of the Fourth Industrial Revolution (Industry 4.0) promoted by the European Community, new approaches have been suggested and adopted in agriculture, giving rise to the so-called Agriculture 4.0. Improvements in automation, advanced information systems and Internet technologies allow for farmers to increase the productivity and to allocate the resources reasonably. For these reasons, agricultural decision support systems (DSS) for Agriculture 4.0 have become a very interesting research topic. DSS are interactive tools that enable users to make informed decisions about unstructured problems, and can be either fully computerized, human or a combination of both. In general, a DSS analyzes and synthesizes large amounts of data to assist in decision making. This paper presents an innovative decision support system solution to address the issues faced by coconut oil producers in making strategic decisions, particularly in the comparison of different methods of oil extraction. In more detail, the adopted methodology describes how to address the problems of coconut oil extraction in order to minimize the processing time and processing cost and to obtain energy savings. To this end, the coconut oil extraction process of the Leão São Tomé and Principe Company is presented as a case study: a DSS instance that analyzes the problem of the optimal selection between two different oil coconut extraction methods (fermentation-based and standard extraction processes) is developed as a meta-heuristics with a mixed integer linear programming problem. The obtained results show that there is clearly a trade-off between the increase in cost and reliability that the decision-maker may be willing to evaluate. In this respect, the proposed model provides a tool to support the decision-maker in choosing the best combination between the two different coconut oil extraction methods. The proposed DSS has been tested in a real application context through an experimental campaign.
\end{abstract}

Keywords: smart farming; Agriculture 4.0; decision support system; decision making; mixed integer linear programming; sustainable farm; coconut oil extraction

\section{Introduction}

Agricultural practice has evolved, following a progressive and long-term process that began from traditional agricultural practice and developed into the so-called Agriculture 4.0 [1]. An example of this evolutionary process is depicted in Figure 1. The process can be reduced to four main steps, spanning Agriculture 1.0 to Agriculture 4.0 [2]. Agriculture 1.0 refers to a traditional approach that is mainly based on manpower and animal forces and where simple tools (e.g., sickles, mattocks, etc.) are used. At this stage, the crop productivity is at a low level. During the 19th century, thanks to the improvements of the steam engines, the Agriculture 2.0 period arose: various agricultural machinery were operated by farmers 
and plenty of chemicals were used. Agriculture 2.0 significantly increased the efficiency and productivity of farm work. However, this increase in productivity brought too harmful problems: field chemical contamination, excessive power consumption, damage of natural resources, etc.. In the 20th century, Agriculture 3.0 emerged thanks to the introduction of information and communication technologies (ICT). In this respect, process automation and robotic techniques allow us to perform operations efficiently: the various production tasks can be repeated in cycles and the production processes can be efficiently monitored in order to prevent system and machine failures [3]. Furthermore, by efficiently distributing the work between the agricultural machinery, the environmental problems induced by Agriculture 2.0 were overcome and a reduction in the use of chemicals and an improvement in the precision of irrigation and so on were obtained. Presently, the evolution of agriculture has moved to Agriculture 4.0. In this respect, Agriculture 4.0 applications are responsible for providing significant improvements to the sector, with a strong economic, environmental and social impact. The main aims of this revolution are related to the introduction of automation and digital technologies (Internet of things-IoT [4], big data, artificial intelligence [5], cloud computing, remote sensing [6], wireless sensor network (WSN) [7,8], etc.) in the agriculture sector, allowing for a transition toward smart and sustainable farming [9]. In Ferrandez-Pastor et al. [10], a low-cost sensor network and actuator platform oriented to IoT applications is presented. In particular, the application aims to optimize the production efficiency by minimizing the environmental impacts and reducing the use of resources such as energy and water. The application of big data to smart farming has been explored in Wolfert et al. [11], whereas Liakos et al. [12] explored the current state of machine learning techniques in agriculture. In Gagliardi et al. [13], a precision farming IoT architecture allowing the farmers to manage and monitor the vineyards' health status was proposed and validated in two experimental sites.

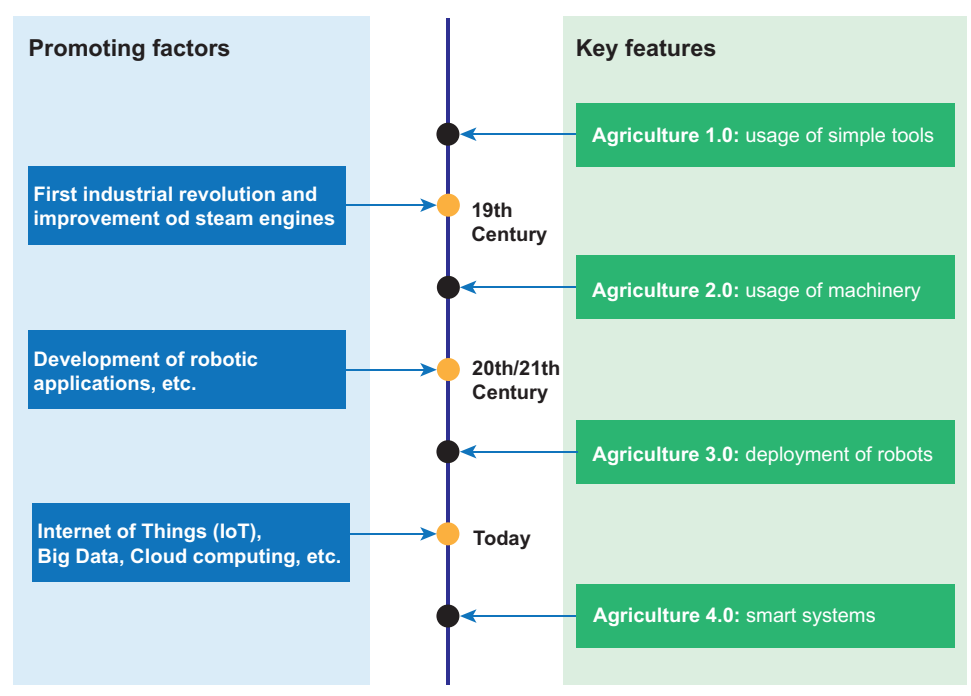

Figure 1. Evolution process from Agriculture 1.0 to Agriculture 4.0.

Despite the introduction of and improvements in digital technologies, due to the increasing amount of information, stakeholders and farmers can encounter some difficulties in making proper decisions about agricultural and production management [14]. Therefore, decision support systems are needed in order to help them to make proper evidence-based decisions. A decision support system (DSS) for agricultural applications can be viewed as a human-computer system that, by analysing heterogeneous data, can provide farmers with a list of advice for supporting their decision making under different conditions. In this respect, the DSS is not only able to provide a list of options for on-going activities, but may also help decision makers to achieve better performances in future tasks [2]. Although DSSs are helpful in farm management, it must be highlighted that the use of such a kind of decision support system has been limited due to some critical issues [15]: farmers have little 
experience or knowledge of using DSSs, the functionality of a DSSs are limited and taskspecific, DSSs are often not user-friendly and it may be confusing for farmers to perform desired actions, etc.

Some successful applications have demonstrated the benefits that the use of DSSs can lead to regarding Agriculture 4.0. The Watson Decision Platform for Agriculture, released by IBM Watson and The Weather Company, is an example of how it is possible to support an organization's requirement to better understand the dynamics of crop production, both realtime and forecast, and ultimately to facilitate improved data-driven decisions. The platform combines agriculture with IBM's advanced capabilities in artificial intelligence, Internet of things and cloud computing (Watson Decision Platform for Agriculture, https:/ /www.ibm. com/downloads/cas/ONVXEB2A, accessed on 20 October 2021). In Bazzani [16], a DSS for the economic-environmental assessment of agricultural activity focusing on irrigation, designed to answer both public and private needs, is presented. This DSS simulates the economically driven decision processes of farmers, permitting an accurate description of production and irrigation in terms of technology and agronomics. At the same time, this DSS oriented to irrigation purposes is able to explore the trade-off among conflicting objectives and offers farmers compromising solutions. In 2013, the German government firstly proposed the Industry 4.0 paradigm [17]; then, two years later, Agriculture 4.0 was defined and quickly attracted wide attentions from worldwide researchers (Agriculture 4.0: The future of farming technology, https:/ / www.worldgovernmentsummit.org/api/publications/document?id=95 df8ac4-e97c-6578-b2f8-ff0000a7ddb6, accessed on 21 October 2021). In this respect, four main requirements are put forward, and are listed as follows: increasing productivity, allocating resources reasonably, adapting to climate change and avoiding food waste [2].

In view of this, the propensity for sustainable development leads to the development of innovative technologies for the agricultural production. Between them, of interest is the production of coconut oil based on the fermentation method, which, unlike other methods, avoids dehydration of the coconut and therefore involves energy savings. With this method, the nutrients of the coconuts remain unchanged for a high quality and eco-sustainable production. Improving the efficiency of energy use (e.g., using less energy to provide the same level of output and service) is widely recognized by many governments as the most costeffective and readily available means to address numerous energy-related issues, including economic impacts of high energy prices and concerns about climate change [18]. At the same time, energy efficiency increases business competitiveness and promotes consumer welfare. Successful energy efficiency projects can bring multiple advantages: technologies that increase energy efficiency can bring improvements to the production process, such as lower operational and maintenance costs, an increased production yield, open outlets in new food markets that require certification of sustainability or energy performance and so on. Accordingly, a comparison for coconut oil extraction between the fermentation method and the standard one requires an effective DSS for the operational and strategic decision making of the decision-makers. Coconut oil producers continuously suffer from a range of issues associated with product quality, changing business environment, technology and consumer preferences. In order to address these issues, the objective of the study was to design an innovative DSS solution to address the issues faced by oil coconut producers, particularly in their implementation of an effective coconut oil extraction method. In particular, this work outlines the development of a DSS designed to assist in the sustainable comparison of coconut oil extraction methods. The decision support system must be able to drive the company manager in the best choice of coconut oil extraction method on the basis of specific requirements: production time, cost minimization and energy savings. The proposed DSS is developed as a meta-heuristics with a mixed integer linear programming problem. The main properties that the proposed approach relies on are its adaptability and flexibility to the needs of the coconut oil producers and its integration capabilities in the smart production application for Agriculture 4.0 and the Web solution. Another important characteristic is related to the fact that the application context of the proposed DSS can be extended to production plants where processing times, costs and energy consumptions 
need to be evaluated (i.e., the coconut extraction oil process selection can be viewed as an application of the proposed DSS).

The paper is organized as follows: Section 2 is devoted to providing a general overview about DSS. Furthermore, the case study of Leão São Tomé and Principe Company is outlined, and details about the accounted coconut oil fermentation-based extraction process are given. The DSS for the best choice of coconut oil extraction method is then presented. Finally, Section 3 reports a discussion about the results obtained, and some conclusions end the paper.

\section{Materials and Methods}

\subsection{Decision Support Systems}

DSS are interactive tools that enable users to make informed decisions about unstructured problems. These systems typically contain a database of information about a problem, a model describing the studied problem and a user interface. Figure 2 shows the components of a typical DSS. There exists a dispute related to which applications can be defined as decision tools. In Kefeer et al. [19], where a study of decision analysis applications has been outlined, it is highlighted that "an application generally had to explicitly analyze alternatives for a decision problem using judgmental probabilities and/or subjectively assessed utility/value functions". Various tools have been developed to address problems pertinent to the water sector. Some examples of tools that assist in making informed decisions, though not necessarily full decision tools, are: "cost-benefit analysis", "multi-criteria analysis", "life cycle analysis", "materials flux analysis" and "environmental impact assessments" [20]. Consideration for the sustainability of solutions has been integrated into some DSSs. Churchill et al. [21], for instance, incorporated sustainable design rules to assist in the development of community growth into their DSS. By considering the economic, environmental and social aspects of a problem and incorporating this information into a DSS, the choice of the best method for the production of coconut oil can be created in such a manner as to remain functioning over the long term. Use of appropriate technologies and incorporation of stakeholder opinions as decisions are made can improve system performance [20].

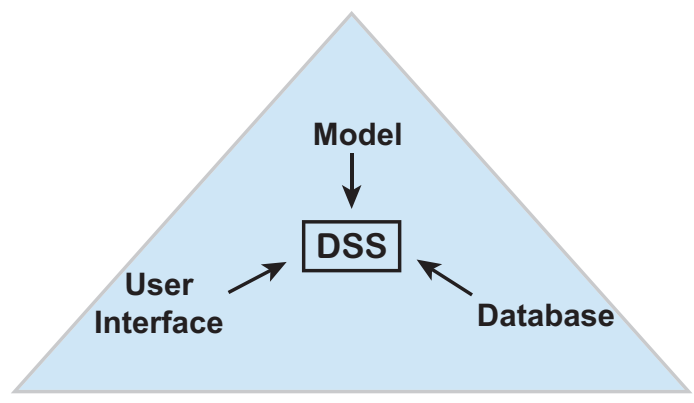

Figure 2. Typical decision support system components [22].

In this paper, the objective is to address the issues faced by coconut oil producers in making strategic decisions, particularly in their comparison of different methods of production. One way to achieve this could be by using a DSS. The concept of DSS originates from the early 1970s and was defined as "interactive computer-based systems, which help decision makers utilize data and models to solve unstructured problems" [23]. According to Turban et al. [23], a DSS is a methodology or an approach for supporting decision making, and the DSS is able to process large amounts of data on a frequent basis. It uses a computerbased information system (CBIS), which is flexible, interactive and adaptable, and is especially developed to solve a specific non-structured management problem. Marakas [24] claims that if firms want to succeed and excel in their markets, they require an information system that can provide decision-makers with relevant decision-supporting information. Furthermore, Turban et al. [23] state that a DSS supports every phase of the decision-making process and can integrate a decision-maker's own insights into the decision support data. 
Marakas [24] defines a DSS as "A decision support system is a system under the control of one or more decision makers that assists in the activity of the decision making by providing an organized set of tools intended to impose structure on portions of the decision-making situation and to improve the ultimate effectiveness of the decision outcome". In 2005, Turban et al. [23] defined a DSS as "... an approach for supporting decision-making". A DSS is also defined as a "computerbased systems that support decision making activities including expert systems and multi-criteria decision analysis" [25]. As one can see by looking at the three definitions above, it seems like there is no exact consensus on what a DSS really is. Therefore, Turban et al. [23] have put together the key characteristics and capabilities of a DSS, which can be seen in Figure 3. With reference to this Figure, a DSS works as a support for decision-makers, mainly in semi-structured and unstructured situations, by combining computerized information and human judgement (1). The DSS also gives support to all decision-makers in every managerial level, from executives to line decision-makers (2), and for both individuals and groups of people (3). The decisions made in conjunction with a DSS can be made once, several times or are repeated (4), and the DSS gives support during the entire decisionmaking process: intelligence, design, choice and implementation (5). A DSS can also support a diversity of decision-making styles and processes (6), and DSSs are adaptable and flexible over time (7). Furthermore, the effectiveness of a DSS can greatly increase with the use of a highly user-friendly human computer interface (8). The improvement given by a DSS is in the effectiveness of decision making (timeliness, quality, accuracy) rather than efficiency (cost of making a decision) (9), and the aim of a DSS is to support the decisionmaker, not to replace him or her (10). Moreover a DSS can be developed and modified by its end-users (11), and the user is able to experiment with different strategies under different configurations because of the DSSs' capability to analyze decision-making situations (12). Finally, a DSS provides access to a diversity of data sources, formats and types because a DSS can be employed as standalone tool for one decision-maker or can be distributed throughout an organization using Web and networking technologies (13 and 14).

\subsection{The Case Study of Leão São Tomé e Principe Company}

Agriculture is faced worldwide with an accelerating transformation. Advances in science and technology, shifting consumption patterns, trade globalization and the impacts of local and global environmental change lead to new risks to agricultural production systems and producers. In view of these changes, sustainability of the agri-food system and farming as a multi-functional enterprise is of increasing importance. At the same time, the expansion of agricultural land and the intensification of production methods have reached their ecological, economic and social limitations. Sustainable production holds the key to finding an answer to these challenges. In recent years, coconut oil has been used both as a food ingredient in functional foods and in pharmaceuticals and cosmetics. Coconut oil is a rich source of medium chain triglycerides (MCTs), which, in general, have a positive impact on health and nutrition. In fact, it is rich in fatty acids (i.e., lauric acid, capric acid, caprylic acid and caproic acid), which provide antimicrobial, antibacterial, antifungal and emollient properties to the coconut oil. Coconut oil is obtained from the fresh and ripe endosperm (kernel/pulp) of the coconut, contains natural vitamin $\mathrm{E}$ and has a very low free fatty acid content $(0.1 \%)$. Coconut oil is unique among all other vegetable oils for its high content of lauric acid. Lauric acid is converted to monolaurin, which provides it with the ability to reduce viral or bacterial infections or protozoal infections [26]. Starting from this premise, this section is devoted to briefly describing the case study of sustainable coconut oil extraction process started by the Leão São Tomé and Principe Company and to compare it with the standard one. 


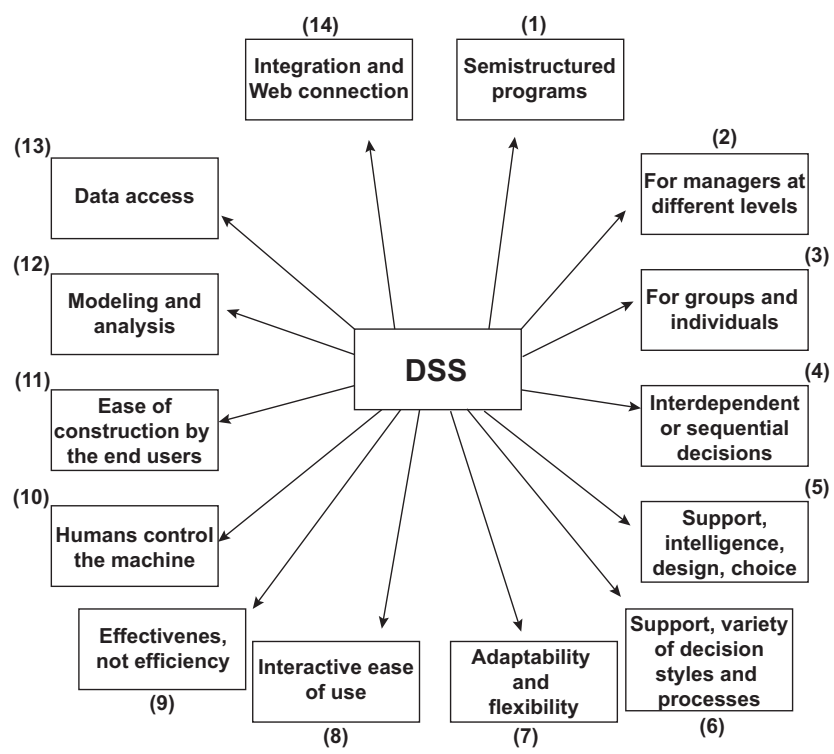

Figure 3. Key characteristics and capabilities of a DSS, adapted from [23].

\subsubsection{Leão São Tomé and Principe Company Coconut Oil Extraction}

Production Architecture

The company coconut oil extraction system can be viewed as a smart framework that includes all of the necessary functions to perform autonomous sensor acquisition, local data storage and remote transmission. All collected data, exchanged by using a sensor network and a base station (network gateway), are shared with the user via the cloud. Therefore, the smart production architecture (Figure 4) provides a web user interface, allowing the users to $\log$ in and display and analyze the historical data series for a single sensor or for a whole plant. The set of sensors is composed of independent devices, each being identified by an ID and responsible for collecting data of a specific production plant part (e.g., bottle pick and place, conveyor belt, etc.). An electronic device autonomously collects the sensor data and then uses a wireless protocol to send the data to the base station. Then, the collected data are sent from the base station (which acts as a gateway) to the cloud through a direct internet connection. It must be highlighted that the collected data refer to the production plant (e.g., energy consumption, produced quantities, etc.), to the coconut oil quality (detection of polyphenols quantity in the oil, etc.) and to the health status of the production plant and its parts (detection of hardware failure conditions). Finally this information is properly elaborated on to update the available raw materials database, to check the quality of the production and to perform, if needed, maintenance activities.

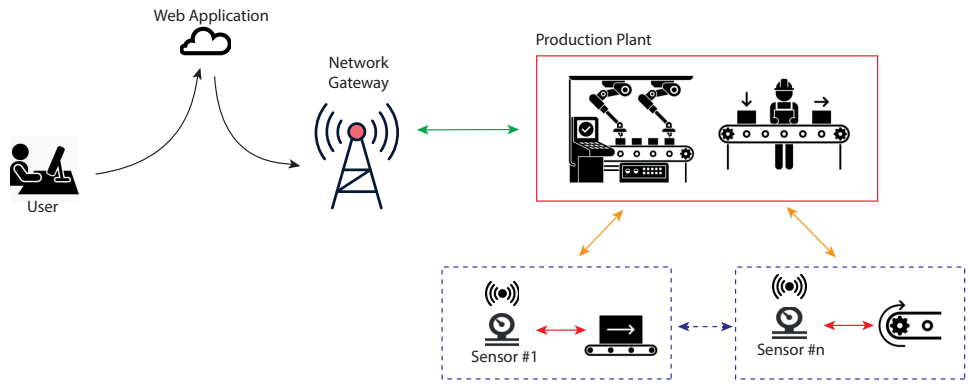

Figure 4. Smart production architecture.

The production plant allows for two kind of production approaches: the first one is a sustainable fermentation-based coconut oil extraction process, and the second one refers to a standard coconut oil extraction process. These approaches are outlined in what follows. 


\subsubsection{Leão São Tomé and Principe Coconut Oil Extraction Processes}

Figures 5 and 6, respectively, describe the main steps both related to the fermentationbased and standard oil coconut extraction process.

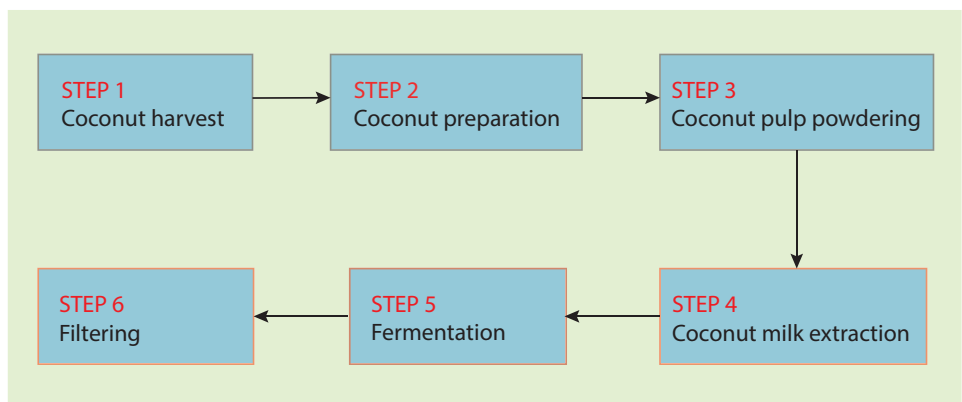

Figure 5. Fermentation-based coconut oil extraction process.

With reference to Figure 5, the fermentation-based coconut extraction process can be described as follows:

- Coconut harvest: the coconut is harvested fully ripe (11-12 months) and selected for oil production. The peel is removed from the coconut using a manual shelling machine;

- Coconut preparation: the coconut is cracked in half;

- Coconut pulp powdering: once split, the coconuts are pressed manually against the rotating blade of the scraping pulp machine. This machine scrapes off the fine pulp of the coconut with the help of a properly designed stainless steel blade. It is important that only the white part of the pulp is scraped off. The capacity of the scraping pulp machine is 60 nuts per hour;

- Coconut milk extraction: the powdered coconut is placed in the manual milk extractor/press (Figure 7a) to produce coconut milk;

- Fermentation: the extracted milk is stirred vigorously for a few minutes and placed, for the fermentation process, in a transparent container, where it will rest for $24 / 36 \mathrm{~h}$ (Figure $7 \mathrm{~b}$ ). Under favorable conditions of temperature and relative humidity, the fermentation process gives rise to high quality coconut oil. The fermentation procedure efficiency is approximately $20-22 \%$ of the weight of the coconut pulp. If the operating and sanitary conditions are correct and precautions are strictly followed, four distinct layers will form in the fermentation container (Figure $7 \mathrm{~b}$ ). The bottom $\left(L_{1}\right)$ consists of a rubbery sediment. The next layer $\left(L_{2}\right)$ is watery and contains fermented skim milk, which is not good for human consumption. The next level $\left(L_{3}\right)$ is the oil to be filtered. The floating top layer $\left(L_{4}\right)$ is the curd. By carefully removing the distinct layers, the oil can be separated;

- Filtering: the oil is filtered until it becomes crystalline. The filtering process can be carried out through sterilized cotton wool filters, filter paper or filter cloth. At the end of the process the oil is stored in stainless steel containers.

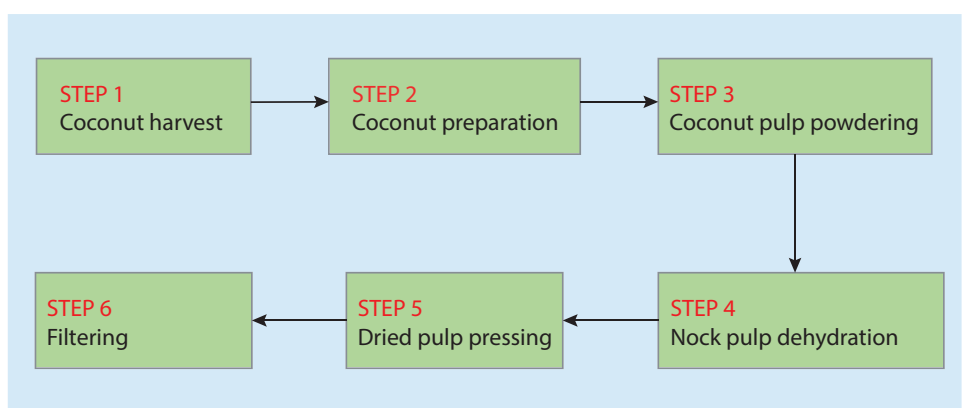

Figure 6. Standard coconut oil extraction process. 
On the other hand, it can be highlighted that the standard extraction process differs from the fermentation-based approach in steps 4 and 5 (refers to Figure 6):

- $\quad$ Nock pulp dehydration: the powdered coconut is placed in the dehydrator (Figure 8a). The dehydration process takes approximately $12 \mathrm{~h}$ at a temperature of approximately $58{ }^{\circ} \mathrm{C}$. The dehydrator capacity is approximately $100 \mathrm{~kg}$ and the energy consumption is approximately $5850 \mathrm{Wh}$;

- Dried pulp pressing: a continuous screw press is used to extract the oil from the dehydrated pulp (Figure $8 \mathrm{~b}$ ). The press capacity is $25 \mathrm{~kg} / \mathrm{h}$ and energy consumption is $1500 \mathrm{Wh}$ ). The extraction process has a yield of $65 \%$;

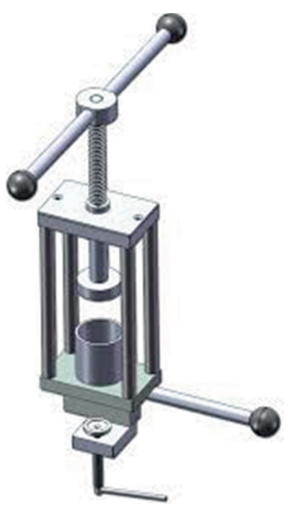

(a)

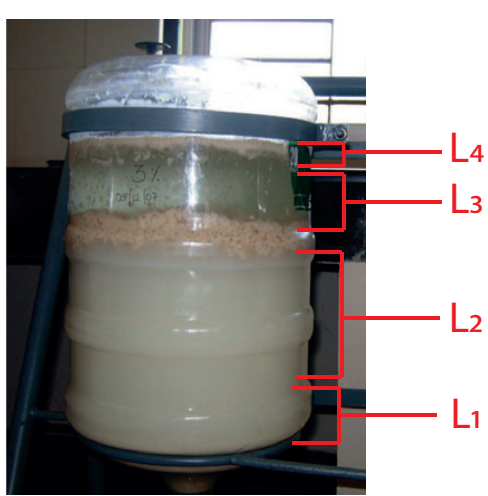

(b)

Figure 7. Coconut fermentation-based oil extraction process: coconut milk extraction machine (a) and coconut milk fermentation container $(\mathbf{b})$.

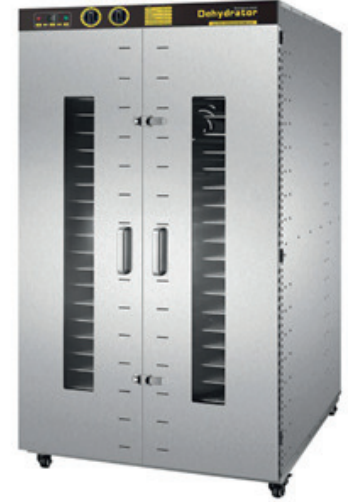

(a)

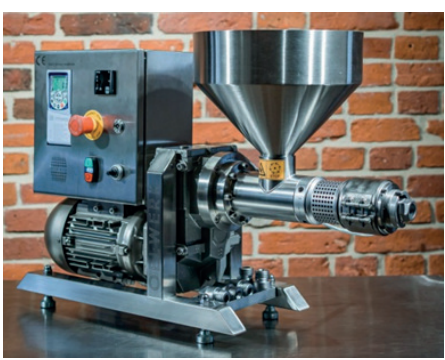

(b)

Figure 8. Coconut dehydration-based oil extraction process: dehydrator (a) and dried pulp press (b).

From the above, it is evident that the fermentation-based coconut oil extraction process avoids the dehydration procedure and the dried pulp pressing step. Consequently this method allows us to reduce the total production energy consumption and costs. It is important to note that, in order to assess the quality of the coconut oil, a preliminary laboratory analysis has been performed. These analyses aim to provide the necessary information related to the quality characteristics of the fermentation-based coconut oil extraction process w.r.t the standard one. The performed analysis shows that the quality of the coconut oil can be improved if a fermentation-based method is accounted for. Table 1 shows the results of this analysis. From this table, it is evident that all chemical parameters assessing the coconut oil quality are greater when a fermentation-based approach is adopted. 
Table 1. Quality characteristics of fermentation-based coconut oil and standard one.

\begin{tabular}{ccc}
\hline Chemical Parameter & Fermentation-Based Method & Standard Method \\
\hline Tocopherol $[\mu / \mathrm{g}]$ & $20-30$ & $2-6$ \\
Polyphenols $[(\mu / \mathrm{g})]$ & $350-500$ & $150-250$ \\
Antioxidant activity [\%] & $65-75$ & $35-45$ \\
Monoglycerides [\&] & $2-3$ & $0.5-1.5$ \\
Phytosterol $(\mu / \mathrm{g})$ & $2-2.5$ & $0.5-1$ \\
Saponification value $[-]$ & $250-260$ & $250-260$ \\
\hline
\end{tabular}

Despite this, the main concerns in the choice of such a kind of sustainable production process are related to the following questions:

- Can this process allow for a production level similar to those pertaining the standard extraction process?

- In which conditions can the fermentation-based method be adopted in place of the standard one?

To give a solution to the above questions it is necessary to adopt a decision support system aimed at addressing the issues faced by coconut oil producers in making strategic decisions. Details about the proposed DSS for the best choice of coconut oil extraction method are presented in the following section.

\subsection{Decision Support System for the Best Choice of Coconut Oil Extraction Method}

This study adopted the design science research methodology to capture the decision problems and to convert them into a set of problem-specific requirements in order to develop the solution. In the specific case, the following methodology describes how to address the problem of coconut oil extraction to minimize the time and cost and to obtain energy savings. The decision-making problem identified was faced with a DSS that developed a meta-heuristics with a mixed integer linear programming problem.

Figure 9 shows the extraction process selection adopted by the Leão São Tomé and Principe Company. The aim of this procedure is to provide the necessary information to the right selection of the production process on the basis of the company needs. The selection procedure is based on the phases described in what follows. In the data collection phase, the information related to the available raw materials and customer orders are collected. This information is properly managed, stored in the cloud and available in real-time so that the company can meet the customer's demands on time. In the pre-processing stage, on the basis of the previous step, the quantity to be produced is determined and, consequently, the production time, cost and energy consumption are estimated. In the subsequent stage, the DSS is responsible for determining which kind of production process must be accounted for on the basis of the quantity to be produced and estimated variables. Human experience is utilized in designing the decision support model. This is made possible by the use of a linear programming approach that is used to frame the solution to a problem in an easily understandable manner. Parameters from pre-processing values will act as membership values that will then be applied to an optimization problem responsible for providing a solution to the production process selection. The input data related to the time, costs and energy consumption were collected through multiple focus group sessions involving oil coconut producers evaluating the different methods of oil extraction. Qualitative and descriptive analysis approaches were adopted to analyze the data. These users evaluated the time, cost, efficacy and performance of the DSS instantiation. The evaluation was critical to producing a user-friendly DSS to meet end-user needs and for further improvements of the DSS instantiation. There are various contributions made throughout this study, creating the bridge between theoretical and practical knowledge. The DSS instance analyzes the problem of the optimal selection between different coconut oil extraction methods. With reference to the case study of the Leão São Tomé and Principe Company, two methods have been accounted for: the standard approach and the fermentation-based one. The standard method involves the following processing phases for the extraction of coconut oil: 
a Coconut harvest:

b Coconut preparation;

c Coconut pulp powdering;

d Nock pulp dehydration;

e Dried pulp pressing;

f Filtering.

The method based on fermentation proposed in this paper, on the other hand, involves the following phases:

a Coconut harvest;

b Coconut preparation;

c Coconut pulp powdering;

d Coconut milk extraction;

e Fermentation;

f Filtering.

In the instantiation of the decision support system, both for the standard method and for the one based on fermentation, each phase is associated with a parameter related to the processing time and one related to the processing cost (raw material, hardware, small parts, maintenance, etc.). In the same way, a parameter on the energy consumed in the various phases is associated. The decision-making approach can be summarized and instantiated as follows:

1. Initialization: set a binary variable of choice $\delta_{i}$ for the reference methods $i=1,2$ : respectively, the standard one $(i=1)$ and the one based on fermentation $(i=2)$. For the different working phases of the $i$-th method $(i=1,2)$, define the processing time $\left(t_{j}\right)$, cost $\left(c_{j}\right)$ and consumption $\left(e c_{j}\right), j=a, \ldots, f$;

2. Generation of parameters: generate the set of parameters relating to times $T_{i}=\sum_{j} t_{j}$, costs $C_{i}=\sum_{j} c_{j}$ and energy consumed $E C_{i}=\sum_{j} e c_{j}$ for each phase $(j=a, \ldots, f)$ of the two methods described $(i=1,2)$; in this phase, the maximum permitted values of the parameters associated with the times $T_{i}^{M A X}$, costs $C_{i}^{M A X}$ and energy consumed $E C_{i}^{M A X}$ are also generated. Define, also, the processing time cost $\left(T C_{i}\right)$ and the energy $\operatorname{cost}\left(E T_{i}\right)$ for the two extraction methods $(i=1,2)$;

3. Definition of the weights of the objective function: in this phase, the weights $\alpha, \beta$ and $\gamma$ for each set of parameters identified above are defined; the objective function is a weighted combination of the maximization of time savings $T S_{i}$, costs savings $C S_{i}$ and energy savings $E S_{i}(i=1,2)$ in the different stages of coconut oil extraction;

4. Search for the solution: solve the following mixed integer linear programming problem to obtain the optimal choice of the coconut oil extraction method to be used:

$$
\left\{\begin{array}{c}
\max \alpha T S_{i}+\beta C S_{i}+\gamma E S_{i} \\
\text { s.t. } \\
T S_{i}=\delta_{i}\left(T_{i}^{M A X}-T_{i}\right) T C_{i} \forall i \\
C S_{i}=\delta_{i}\left(C_{i}^{M A X}-C_{i}\right) \forall i \\
E S_{i}=\delta_{i}\left(E C_{i}^{M A X}-E C_{i}\right) E T_{i} \forall i \\
\sum_{i} \delta_{i}=1, \\
\delta \in\{0,1\}
\end{array}\right.
$$

5. Validation of results: compare the results obtained in terms of their objective function by the two extraction methods;

6. Choice of method: the method based on fermentation, with the same processing times and costs, minimizes the natural resources used and produces significant energy savings;

7. Stop 


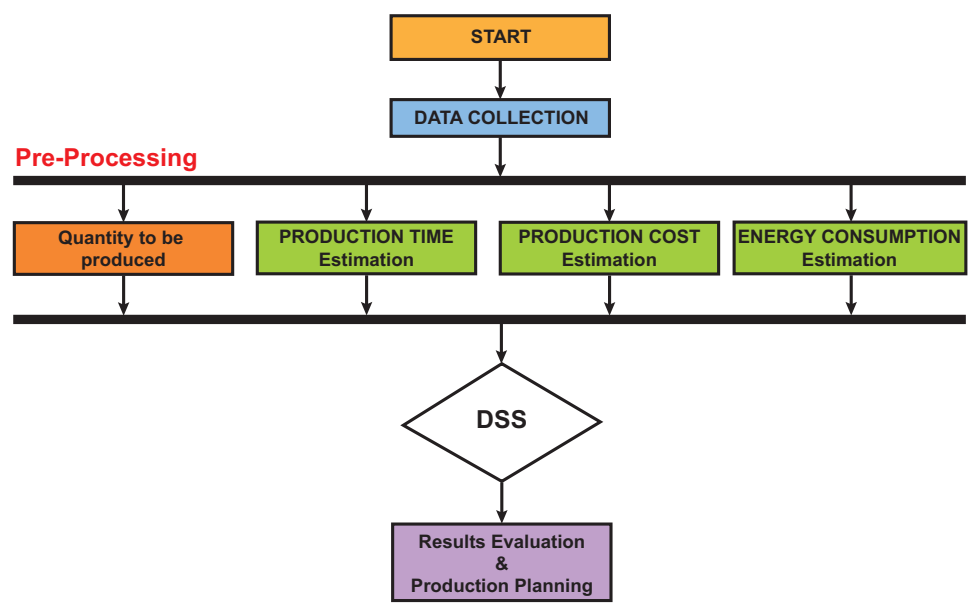

Figure 9. Extraction process selection.

\section{Results and Discussion}

This section focuses on the application of the decision-making approach (1) by accounting for, as the case study, the fermentation-based coconut oil extraction process used within the company Leão São Tomé and Principe Company and the standard extraction process. The functional unit (FU) for this study, towards which, all the impacts were allocated, was defined as $1 \mathrm{~kg}$ of coconut oil produced. The system boundaries involved in this study are the processing phases for the extraction of coconut oil described in Section 2.2.1: coconut harvest, coconut preparation, coconut pulp powdering, nock pulp dehydration (coconut milk extraction), dried pulp pressing (fermentation) and filtering. Downstream activities (e.g., distribution and use) are not part of this study. Process flow diagrams have been used to outline the relationships between unit processes and flows across the system boundaries. Primary data sources have been obtained in situ, whereas information was collected through personal interviews with the plant manager and the workers, observation of the power rating, efficiency of the used machinery (dehydrator and dried pulp press) and measurement of the mass flow in the plant.

In this respect, in order to instantiate the decision-making approach, the variables reported in Tables 2 and 3 have been accounted for, respectively, the standard extraction method $(i=1)$ and fermentation-based extraction method $(i=2)$. The tables report the information about the processing time, costs and rated energy consumptions for both extraction methods. These tables also report the necessary data needed to solve the optimization problem (1).

Table 2. Life cycle inventory (LCI) data: decision-making approach variables for standard extraction $\operatorname{method}(i=1)$.

\begin{tabular}{llc}
\hline Variable & Description & Value \\
\hline$t_{a}$ & Coconut harvest processing time & $8 \mathrm{~h}$ \\
$t_{b}$ & Coconut preparation processing time & $2 \mathrm{~h}$ \\
$t_{c}$ & Coconut pulp powdering processing time & $2 \mathrm{~h}$ \\
$t_{d}$ & Nock pulp dehydration processing time & $12 \mathrm{~h}$ \\
$t_{e}$ & Dried pulp pressing processing time & $4 \mathrm{~h}$ \\
$t_{f}$ & Filtering processing time & $5 \mathrm{~h}$ \\
\hline$c_{a}$ & Coconut harvest fixed cost & $\mathrm{USD} 8$ \\
$c_{b}$ & Coconut preparation fixed cost & $\mathrm{USD} 7$ \\
$c_{c}$ & Coconut pulp powdering fixed cost & $\mathrm{USD} 2$ \\
$c_{d}$ & Nock pulp dehydration fixed cost & $\mathrm{USD} 19.5$ \\
$c_{e}$ & Dried pulp pressing fixed cost & $\mathrm{USD} 5$ \\
$c_{f}$ & Filtering fixed cost & $\mathrm{USD} 8$ \\
\hline
\end{tabular}


Table 2. Cont.

\begin{tabular}{llc}
\hline Variable & Description & Value \\
\hline$\overline{e c}_{a}$ & Coconut harvest energy consumption & $0.075 \mathrm{kWh}$ \\
$\bar{e} c_{b}$ & Coconut preparation energy consumption & $0.075 \mathrm{kWh}$ \\
$\overline{e c} c_{c}$ & Coconut pulp powdering energy consumption & $0.075 \mathrm{kWh}$ \\
$\overline{e c_{d}}$ & Nock pulp dehydration energy consumption & $5.85 \mathrm{kWh}$ \\
$\overline{e c_{e}}$ & Dried pulp pressing energy consumption & $1.5 \mathrm{kWh}$ \\
$\overline{e c} c_{f}$ & Filtering energy consumption & $0 \mathrm{kWh}$ \\
\hline$T^{M A X}$ & Maximum allowed total processing time & $50 \mathrm{~h}$ \\
$C^{M A X}$ & Maximum allowed total cost & $\mathrm{USD} 100$ \\
$E C^{M A X}$ & Maximum allowed total energy consumption & $100 \mathrm{kWh}$ \\
\hline$T C$ & Processing time cost & $\mathrm{USD} 7 / \mathrm{h}$ \\
$E T$ & Energy cost & $\mathrm{USD} 1.2 / \mathrm{kWh}$ \\
\hline
\end{tabular}

Table 3. Life cycle inventory (LCI) data: decision-making approach variables for fermentation-based extraction method $(i=2)$.

\begin{tabular}{|c|c|c|}
\hline Variable & Description & Value \\
\hline$t_{a}$ & Coconut harvest processing time & $8 \mathrm{~h}$ \\
\hline$t_{b}$ & Coconut preparation processing time & $2 \mathrm{~h}$ \\
\hline$t_{c}$ & Coconut pulp powdering processing time & $2 \mathrm{~h}$ \\
\hline$t_{d}$ & Coconut milk extraction processing time & $8 \mathrm{~h}$ \\
\hline$t_{e}$ & Fermentation processing time & $27 \mathrm{~h}$ \\
\hline$t_{f}$ & Filtering processing time & $5 \mathrm{~h}$ \\
\hline$c_{a}$ & Coconut harvest fixed cost & USD 8 \\
\hline$c_{b}$ & Coconut preparation fixed cost & USD 7 \\
\hline$c_{c}$ & Coconut pulp powdering fixed cost & USD 2 \\
\hline$c_{d}$ & Coconut milk extraction fixed cost & USD 3 \\
\hline$c_{e}$ & Fermentation fixed cost & USD 5 \\
\hline$c_{f}$ & Filtering fixed cost & USD 8 \\
\hline$\overline{e_{c}}{ }_{a}$ & Coconut harvest energy consumption & $0.075 \mathrm{kWh}$ \\
\hline$\overline{e_{c}} b$ & Coconut preparation energy consumption & $0.075 \mathrm{kWh}$ \\
\hline$\overline{e_{\bar{c}}}$ & Coconut pulp powdering energy consumption & $0.075 \mathrm{kWh}$ \\
\hline$\overline{e c} c_{d}$ & Coconut milk extraction energy consumption & $0.075 \mathrm{kWh}$ \\
\hline$\overline{e c} c_{e}$ & Fermentation energy consumption & $0 \mathrm{kWh}$ \\
\hline$\overline{e c}_{f}$ & Filtering energy consumption & $0 \mathrm{kWh}$ \\
\hline$T^{M A X}$ & Maximum allowed total processing time & $70 \mathrm{~h}$ \\
\hline$C^{M A X}$ & Maximum allowed total cost & USD 100 \\
\hline$E C^{M A X}$ & Maximum allowed total energy consumption & $100 \mathrm{kWh}$ \\
\hline$T C$ & Processing time cost & USD $7 / h$ \\
\hline$E T$ & Energy cost & USD $1.2 / \mathrm{kWh}$ \\
\hline
\end{tabular}

For each extraction method $(i=1,2)$, the energy consumptions $\left(e c_{j}, j=a, \ldots, f\right)$ in $[\mathrm{kWh}]$ was obtained by multiplying the rated consumption of each phase $\left(\bar{e}_{j}, j=a, \ldots, f\right)$ involved in the extraction process with the corresponding hours of operation $\left(t_{j}, j=a, \ldots, f\right)$ :

$$
e c_{j}=t_{j} * \overline{e c}_{j}, j=a, \ldots f
$$

In this respect, we highlight that, according to Odigboh (1998) [27], as reported by Bamgboye and Jekayinfa (2006) [28], the physical power (consumption) output of a normal human operator in tropical climates is approximately $0.075 \mathrm{kWh}$. Then, for the extraction phases where only the human operators are directly involved, the following manual energy consumption can be roughly estimated: 


$$
e c_{j}=\underbrace{0.075}_{\overline{e c}_{j}} * N * t_{j}
$$

where $N$ is the number of people involved in the extraction operation and with

$$
\left\{\begin{array}{l}
j=a, \ldots, c, \text { if } i=1 \\
j=a, \ldots, d, \text { if } i=2 .
\end{array}\right.
$$

Consequently, considering that $N=7$ operators are involved in the production phases, the energy consumption input $\left(E C_{i}, i=1,2\right)$ is:

$$
\left\{\begin{array}{l}
E C_{i=1}=\sum_{j} t_{j} * \overline{e c}_{j}=\sum_{j} e c_{j}=82.5 \mathrm{kWh}, j=a, \ldots, f \\
E C_{i=2}=\sum_{j} t_{j} * \overline{e c}_{j}=\sum_{j} e c_{j}=10.5 \mathrm{kWh}, j=a, \ldots, f
\end{array}\right.
$$

Furthermore, for each extraction method $(i=1,2)$, the total time expended in the extraction process and the production fixed costs are computed as:

$$
\begin{array}{r}
\left\{\begin{array}{l}
T_{i=1}=\sum_{j} t_{j}=33 \mathrm{~h}, j=a, \ldots, f \\
T_{i=2}=\sum_{j} t_{j}=55 \mathrm{~h}, j=a, \ldots, f
\end{array}\right. \\
\left\{\begin{array}{l}
C_{i=1}=\sum_{j} c_{j}=42 \$, j=a, \ldots, f \\
C_{i=2}=\sum_{j} c_{j}=33 \$, j=a, \ldots, f
\end{array}\right.
\end{array}
$$

The optimization problem (1) has been solved for different values of weights $\alpha, \beta$ and $\gamma$ in order to evaluate the proposed DSS performance for an extraction process accounting of $1000 \mathrm{~kg}$ of raw material (it is worth noting that, in general, the production yield is $\approx 20 \%$ ). The results of this evaluation are reported in the following sections.

\subsection{Test 1}

The first test aims to evaluate a condition where the weights in the optimization problem (1) are chosen as

$$
\alpha=0.34 ; \beta=0.33 ; \gamma=0.33 \text {. }
$$

Such a choice implies that, in the resolution of the optimization problem, the processing times, costs and energy savings are of the same importance. Then, by accounting for each extraction method $(i=1,2)$ :

- The inputs computed as in (5)-(7);

- $\quad$ The maximum allowed total processing time $\left(T_{i}^{M A X}\right)$;

- $\quad$ The maximum allowed total cost $\left(C_{i}^{M A X}\right)$;

- $\quad$ The maximum allowed total energy consumption $\left(E C_{i}^{M A X}\right)$;

- $\quad$ The processing time $\left(T C_{i}\right)$ and energy $(E T)$ costs;

if we indicate with $O b j$ the value of the objective function computed for the fermentationbased extraction process $(i=1)$ and the standard one $(i=2)$, the results reported in Table 4 were obtained by solving the optimization problem (1).

Table 4. DSS results.

\begin{tabular}{ccccc}
\hline $\boldsymbol{i}$ & $\boldsymbol{T S}$ & $\boldsymbol{C S}$ & $\boldsymbol{E S}$ & $\boldsymbol{O b j}$ \\
\hline 1 & 833 & 58 & 21 & 309.29 \\
2 & 882 & 67 & 107.4 & 357.43 \\
\hline
\end{tabular}

Then, the optimization problem provides the following result:

$$
\max \left(O b j_{1}, O b j_{2}\right)=O b j_{2}=357.43
$$




\subsection{Test 2}

The second test aims to evaluate a condition where the weights in the optimization problem (1) are chosen as

$$
\alpha=0.8 ; \beta=0.1 ; \gamma=0.1 \text {. }
$$

Such a choice implies that, in the resolution of the optimization problem, the time saving has more weight than costs and energy savings. Then, by accounting for each extraction method $(i=1,2)$ :

- $\quad$ The inputs computed as in (5)-(7);

- $\quad$ The maximum allowed total processing time $\left(T_{i}^{M A X}\right)$;

- $\quad$ The maximum allowed total cost $\left(C_{i}^{M A X}\right)$;

- The maximum allowed total energy consumption $\left(E C_{i}^{M A X}\right)$;

- $\quad$ The processing time $\left(T C_{i}\right)$ and energy $(E T)$ costs;

if we indicate with $\mathrm{Obj}$ the value of the objective function computed for the fermentationbased extraction process $(i=1)$ and the standard one $(i=2)$, the results reported in Table 5 are obtained.

Table 5. DSS results.

\begin{tabular}{ccccc}
\hline $\boldsymbol{i}$ & $\boldsymbol{T S}$ & $\boldsymbol{C S}$ & $\boldsymbol{E S}$ & $\boldsymbol{O b j}$ \\
\hline 1 & 833 & 58 & 21 & 674.3 \\
2 & 882 & 67 & 107.4 & 723.04 \\
\hline
\end{tabular}

Then, the optimization problem provides the following result:

$$
\max \left(\mathrm{Obj}_{1}, \mathrm{Obj}_{2}\right)=\mathrm{Obj}_{2}=723.04
$$

\subsection{Test 3}

This test is devoted to evaluating a condition where the weights in the optimization problem (1) are chosen as

$$
\alpha=0.2 ; \beta=0.4 ; \gamma=0.4 \text {. }
$$

Such a choice implies that, in the resolution of the optimization problem, the costs and energy saving have more weight than the time saving. Then, by accounting for each extraction method $(i=1,2)$ :

- The inputs computed as in (5)-(7);

- $\quad$ The maximum allowed total processing time $\left(T_{i}^{M A X}\right)$;

- $\quad$ The maximum allowed total cost $\left(C_{i}^{M A X}\right)$;

- $\quad$ The maximum allowed total energy consumption $\left(E C_{i}^{M A X}\right)$;

- $\quad$ The processing time $\left(T C_{i}\right)$ and energy $(E T)$ costs;

if we indicate with $\mathrm{Obj}$ the value of the objective function computed for the fermentationbased extraction process $(i=1)$ and the standard one $(i=2)$, the results reported in Table 6 have been obtained.

Table 6. DSS results.

\begin{tabular}{ccccc}
\hline $\boldsymbol{i}$ & TS & CS & ES & Obj \\
\hline 1 & 833 & 58 & 21 & 198.2 \\
2 & 882 & 67 & 107.4 & 246.16 \\
\hline
\end{tabular}

Then, the optimization problem provides the following result:

$$
\max \left(O b j_{1}, O b j_{2}\right)=O b j_{2}=246.16
$$




\subsection{Test 4}

In order to verify the effectiveness of the proposed DSS in various working operating modes, a further 15 experiments, for fixed value of weights $\alpha=0.34, \beta=0.33$ and $\gamma=0.33$, have been performed, by accounting for each experiment:

- Variations in processing time $\left(T_{i}\right)$ : this implies that, with respect to the values reported in Tables 2 and 3 , each phase $(j=a, \ldots, f)$ of the extraction process has a variable execution time;

- Variations in fixed costs $\left(C_{i}\right)$ : this implies that, with respect to the values reported in Tables 2 and 3 , the fixed costs of each phase $(j=a, \ldots, f)$ of the extraction process can change from one period to another;

- Variations in energy consumption $\left(E_{i}\right)$ according to the variations in processing time;

- Variations in energy costs $(E T)$.

Figure 10 shows the aforementioned variations whereas Figure 11 shows, for each test, the value of the objective functions $\left(O b j_{1}\right.$ and $\left.O b j_{2}\right)$ and the output of the DSS procedure $\left(\max \left(O b j_{1}, \mathrm{Obj}_{2}\right)\right.$ - green line). The numerical results of these tests are reported in Table 7.

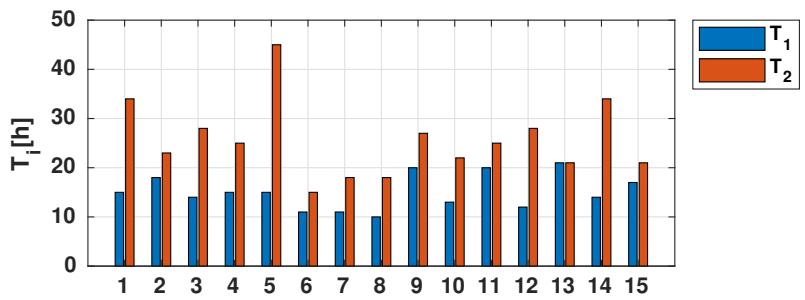

(a)

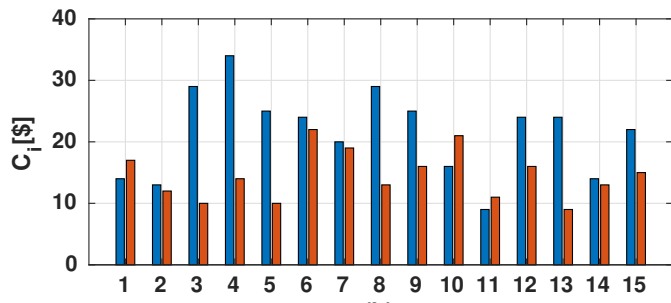

(b)
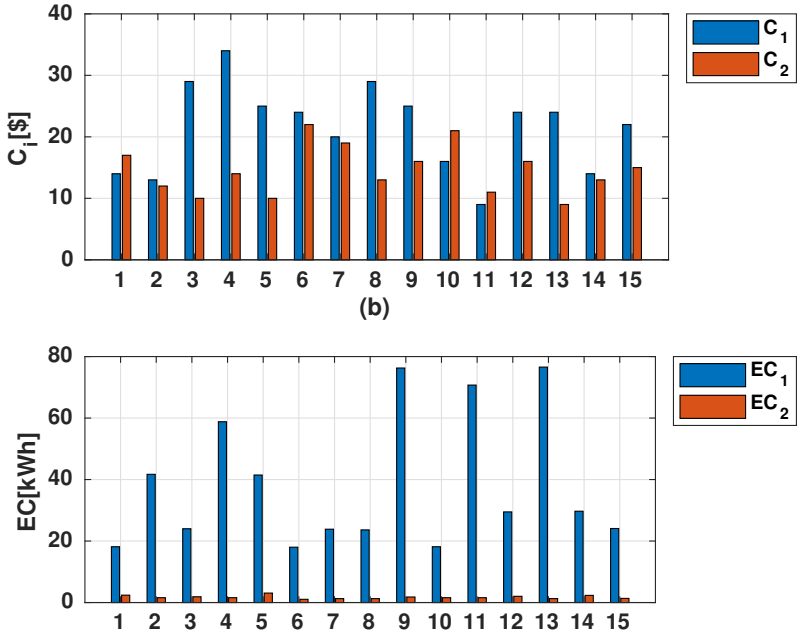

(c)

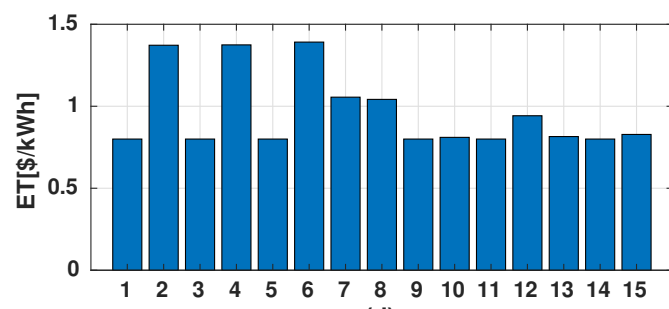

(d)

Figure 10. Test 4-processing times (a), costs (b), energy consumption (c) and energy cost (d) variations. In sub-figure $(\mathbf{a}-\mathbf{c})$, blue bar and red bar refer to the standard $(i=1)$ and fermentation-based $(i=2)$ extraction process, respectively. The x-label refers to the number of performed tests. 


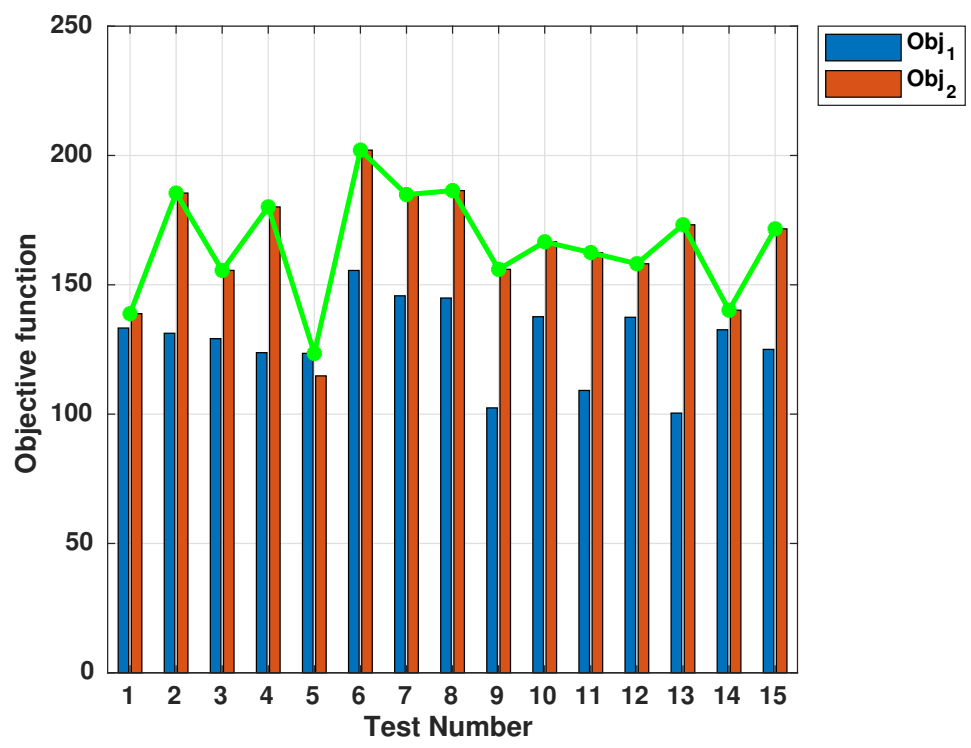

Figure 11. Test 4-objective functions $\mathrm{Obj}_{1}$ (blue bar: standard extraction process), $\mathrm{Obj}_{2}$ (red bar: fermentation-based extraction process) and $\max \left(\mathrm{Obj}_{1}, \mathrm{Obj}_{2}\right)$ (green line).

Table 7. Test 4-DSS results for $\alpha=0.34, \beta=0.33$ and $\gamma=0.33$ and variations in processing time $\left(T_{1,2}\right)$, costs $\left(C_{1,2}\right)$, energy consumption $\left(E C_{1,2}\right)$ and energy costs $(E T)$.

\begin{tabular}{ccccccccccc}
\hline Test & $\boldsymbol{T}_{\mathbf{1}}$ & $\boldsymbol{T}_{\mathbf{2}}$ & $\boldsymbol{C}_{\mathbf{1}}$ & $\boldsymbol{C}_{\mathbf{2}}$ & $\boldsymbol{E C _ { \mathbf { 1 } }}$ & $\boldsymbol{E C _ { \mathbf { 2 } }}$ & $\boldsymbol{E T}$ & $\boldsymbol{O b j}_{\mathbf{1}}$ & $\boldsymbol{O b j}_{\mathbf{2}}$ & $\mathbf{M a x}$ \\
\hline 1 & 15 & 34 & 14 & 17 & 18.15 & 2.4 & 0.8 & 133.28 & $\mathbf{1 3 8 . 8 3}$ & 138.83 \\
2 & 18 & 23 & 13 & 12 & 41.7 & 1.575 & 1.3722 & 131.26 & $\mathbf{1 8 5 . 4 6}$ & 185.46 \\
3 & 14 & 28 & 29 & 10 & 24 & 1.875 & 0.8 & 129.17 & $\mathbf{1 5 5 . 5 6}$ & 155.56 \\
4 & 15 & 25 & 34 & 14 & 58.8 & 1.575 & 1.3743 & 123.76 & $\mathbf{1 8 0 . 1 1}$ & 180.11 \\
5 & 15 & 45 & 25 & 10 & 41.475 & 3.075 & 0.8 & $\mathbf{1 2 3 . 5 0}$ & 114.78 & 123.50 \\
6 & 11 & 15 & 24 & 22 & 18 & 1.05 & 1.3913 & 155.54 & $\mathbf{2 0 2 . 0 7}$ & 202.07 \\
7 & 11 & 18 & 20 & 19 & 23.85 & 1.275 & 1.0555 & 145.74 & $\mathbf{1 8 4 . 8 7}$ & 184.87 \\
8 & 10 & 18 & 29 & 13 & 23.625 & 1.275 & 1.042 & 144.89 & $\mathbf{1 8 6 . 4 1}$ & 186.41 \\
9 & 20 & 27 & 25 & 16 & 76.275 & 1.8 & 0.8 & 102.41 & $\mathbf{1 5 5 . 9 8}$ & 155.98 \\
10 & 13 & 22 & 16 & 21 & 18.15 & 1.575 & 0.81033 & 137.66 & $\mathbf{1 6 6 . 6 2}$ & 166.62 \\
11 & 20 & 25 & 9 & 11 & 70.725 & 1.575 & 0.8 & 109.15 & $\mathbf{1 6 2 . 4 5}$ & 162.45 \\
12 & 12 & 28 & 24 & 16 & 29.475 & 2.025 & 0.94219 & 137.44 & $\mathbf{1 5 8 . 1 4}$ & 158.14 \\
13 & 21 & 21 & 24 & 9 & 76.575 & 1.275 & 0.8153 & 100.40 & $\mathbf{1 7 3 . 2 1}$ & 173.21 \\
14 & 14 & 34 & 14 & 13 & 29.7 & 2.325 & 0.8 & 132.61 & $\mathbf{1 4 0 . 1 7}$ & 140.17 \\
15 & 17 & 21 & 22 & 15 & 24.075 & 1.35 & 0.82816 & 125.02 & $\mathbf{1 7 1 . 6 3}$ & 171.63 \\
\hline
\end{tabular}

In Appendix A, the input data for this test are reported.

\subsection{Discussion}

The analysis of the results states that there is clearly a trade-off between the increase in cost and the reliability that the decision-maker may be willing to evaluate. In this respect, the proposed model provides a tool to support the decision-maker in choosing the best combination between the two different coconut oil extraction methods. In particular, the performed tests show that, for the considered quantity of raw materials, except for experiment 5 of Test 4 , the DSS provides as optimal solution for the extraction process: the fermentation-based one. In more detail, with reference to experiment 5 of Test 4 , it is interesting to observe that the standard process is indicated as a better solution for the extraction procedure. This is mainly due to the fact that this experiment is characterized by a high value of processing time $T_{2}=45$. Therefore, this result highlights that the standard process is preferable to the fermentation-based one when the processing times are $T_{2}>>T_{1}$. However, despite this, the computational results carried out by considering a real case study show the validity of the extraction coconut oil method based on fermentation as the best choice for coconut oil producers. Starting from these results, it is easy to verify that, 
through additional experiments, the proposed methodology can be adopted as a decision support system in a real setting for coconut oil producers. To this end, further analysis will be aimed at evaluating the proposed oil coconut extraction methods by considering the real evolution of the energy market prices, the availability of natural resources and the demand consumption requirements of the different production phases.

Furthermore, with reference to Figure 3, the key characteristics and capabilities of the proposed DSS are listed as follows:

1. Semi-structured programs: computerized information (production time, cost and energy consumption estimations) and human judgement (e.g., number of operators involved in the production process, etc.) are combined;

2. For managers at different levels-for groups and individuals: the company owners are supported in choosing the better coconut oil extraction process and in planning the operator activities;

3. Interdependent or sequential decisions: the decisions made in conjunction with the DSS can be repeated several times;

4. Support, intelligence, design, choice: the presented DSS is developed as a metaheuristics with a mixed integer linear programming problem. The DSS instance analyzes the problem of the choice between two different oil coconut extraction methods;

5. Support, variety of decision styles and processes: the proposed DSS can be applied to production plants where processing times, costs and energy consumption need to be evaluated (i.e., olive oil production plant, wine production plant and so on);

6. Adaptability and flexibility: the DSS is adaptive and can be configured on the basis of the current needs of the company. As an example, the DSS can match different objectives on the basis of the values of the weights $\alpha, \beta$ and $\gamma$;

7. Interactive ease of use: the proposed DSS can be easily presented with a fully accessible user interface;

8. Effectiveness, not efficiency: the DSS provides accuracy in the choice of coconut oil extraction method;

9. Humans control the machine: the presented DSS is aimed at supporting the decision maker;

10. Ease of construction by the end-users: the DSS can be modified by the user. In this respect, the user can modify some DSS parameters as the maximum allowed total processing time $\left(T^{M A X}\right)$, maximum allowed total cost $\left(C^{M A X}\right)$, maximum allowed total energy consumption $\left(E C^{M A X}\right)$, processing time cost $(T C)$ and energy cost $(E C)$;

11. Modeling and analysis: the user is able to experiment with different strategies;

12. Data access - integration and Web connection: the presented DSS can be employed both as a standalone and through the Web (in fact, the DSS is integrated in a J2EE platform).

\section{Conclusions}

The paper presents a decision support system for sustainable agriculture. In more detail, the main goal of this study was to design a DSS solution capable of supporting farmers in making the best choice between different production methods. In this respect, moving from the case study of the coconut oil extraction process, the primary objective was to propose a procedure whose application context can be easily extended to all production processes, where processing times, costs and energy consumption need to be evaluated. A secondary aspect to be highlighted is related to the fact that the presented DSS has been designed to be as simple as possible. This design choice is mainly due to the fact that the aim is to provide a user-friendly DSS solution that allows for the evaluation of different production scenarios: the DSS can be customized by the user, who can modify some parameters and the weights in the objective function. The problem has been solved by recasting the DSS conceptualization into a mixed integer linear programming problem. The DSS is responsible for evaluating the company production needs and, on the basis of the quantity to be produced, estimated production time, costs and energy consumptions, 
provides the necessary information to the right selection of the production process. In the specific case of study, the DSS has been validated through an experimental campaign. In this respect, the DSS performance has been evaluated for different values of the weight in the objective function. The computational results show the validity of the extraction coconut oil method based on fermentation as the best choice for coconut oil producers. At the same time, the validation activity shows that, when the processing time of the fermentationbased approach is higher than the standard one (i.e., a high production is needed), the standard approach is preferable. In this regard, the proposed approach provides a tool (fully integrable in smart production architecture for Agriculture 4.0) to support the decisionmaker in choosing the best combination between different production methods. Starting from the obtained promising results, future works will be addressed in order to analyze and evaluate the proposed DSS solution by considering the real evolution of the energy market prices, the availability of natural resources and the demand consumption requirements of the different production phases. Moreover, further investigation will be oriented to evaluate the DSS capabilities in other application fields, such as olive oil production plants, wine production plants and so on. Finally, the experimental stage has suggested that the main benefits due to the introduction of the proposed DSS can be summarized as a greater production quality and efficiency, reduction in company costs, optimization of inputs and minimization of environmental impact.

Author Contributions: Conceptualization, G.G.; data curation, G.G.; investigation, A.I.M.C.; project administration, F.M. and G.G.; resources F.M.; software, A.I.M.C. and G.G.; supervision, F.M.; validation, A.I.M.C.; writing-original draft, G.G. and A.I.M.C.; writing-review and editing, G.G. and A.I.M.C. All authors have read and agreed to the published version of the manuscript.

Funding: This research received no external funding.

Institutional Review Board Statement: Not applicable.

Informed Consent Statement: Not applicable.

Data Availability Statement: Data available on request due to privacy.

Conflicts of Interest: The authors declare no conflict of interest.

\section{Appendix A}

In Tables A1-A6, the input data for the Test 4 reported in Section 3.4 are reported.

Table A1. Processing times for standard extraction method $(i=1)$.

\begin{tabular}{|c|c|c|c|c|c|c|c|}
\hline Test & $t_{a} \mathrm{~h}$ & $t_{b} \mathrm{~h}$ & $t_{c} \mathbf{h}$ & $t_{d} \mathbf{h}$ & $t_{e} \mathbf{h}$ & $t_{f} \mathbf{h}$ & $T_{1}$ \\
\hline 1 & 6 & 1 & 1 & 1 & 2 & 4 & 15 \\
\hline 2 & 7 & 1 & 2 & 5 & 2 & 1 & 18 \\
\hline 3 & 6 & 1 & 1 & 1 & 3 & 2 & 14 \\
\hline 4 & 2 & 1 & 1 & 9 & 1 & 1 & 15 \\
\hline 5 & 4 & 1 & 2 & 4 & 3 & 1 & 15 \\
\hline 6 & 2 & 2 & 2 & 2 & 1 & 2 & 11 \\
\hline 7 & 4 & 1 & 1 & 1 & 3 & 1 & 11 \\
\hline 8 & 1 & 1 & 1 & 1 & 3 & 3 & 10 \\
\hline 9 & 1 & 1 & 1 & 11 & 2 & 4 & 20 \\
\hline 10 & 5 & 1 & 2 & 2 & 1 & 2 & 13 \\
\hline 11 & 4 & 1 & 2 & 11 & 1 & 1 & 20 \\
\hline 12 & 1 & 1 & 1 & 4 & 1 & 4 & 12 \\
\hline 13 & 4 & 2 & 1 & 11 & 2 & 1 & 21 \\
\hline 14 & 4 & 1 & 1 & 4 & 1 & 3 & 14 \\
\hline 15 & 6 & 1 & 2 & 1 & 3 & 4 & 17 \\
\hline
\end{tabular}


Table A2. Processing times for fermentation-based extraction method $(i=2)$.

\begin{tabular}{cccccccc}
\hline Test & $\boldsymbol{t}_{\boldsymbol{a}} \mathbf{h}$ & $\boldsymbol{t}_{\boldsymbol{b}} \mathbf{h}$ & $\boldsymbol{t}_{\boldsymbol{c}} \mathbf{h}$ & $\boldsymbol{t}_{\boldsymbol{d}} \mathbf{h}$ & $\boldsymbol{t}_{\boldsymbol{e}} \mathbf{h}$ & $\boldsymbol{t}_{\boldsymbol{f}} \mathbf{h}$ & $\boldsymbol{T}_{\mathbf{1}}$ \\
\hline 1 & 4 & 1 & 2 & 2 & 23 & 2 & 34 \\
2 & 7 & 2 & 1 & 4 & 7 & 2 & 23 \\
3 & 2 & 1 & 2 & 6 & 14 & 3 & 28 \\
4 & 4 & 1 & 1 & 1 & 14 & 4 & 25 \\
5 & 7 & 1 & 2 & 5 & 26 & 4 & 45 \\
6 & 1 & 1 & 2 & 3 & 7 & 1 & 15 \\
7 & 6 & 1 & 1 & 2 & 7 & 1 & 18 \\
8 & 1 & 2 & 1 & 5 & 8 & 1 & 18 \\
9 & 3 & 1 & 2 & 3 & 15 & 3 & 27 \\
10 & 7 & 2 & 1 & 1 & 10 & 1 & 22 \\
11 & 5 & 2 & 1 & 7 & 6 & 4 & 25 \\
12 & 3 & 1 & 1 & 4 & 18 & 1 & 28 \\
13 & 4 & 1 & 1 & 4 & 7 & 4 & 21 \\
14 & 1 & 2 & 1 & 2 & 25 & 3 & 34 \\
15 & 1 & 1 & 2 & 1 & 13 & 3 & 21 \\
\hline
\end{tabular}

Table A3. Costs for standard extraction method $(i=1)$.

\begin{tabular}{cccccccc}
\hline Test & $\boldsymbol{c}_{\boldsymbol{a}} \boldsymbol{\$}$ & $\boldsymbol{c}_{\boldsymbol{b}} \boldsymbol{\$}$ & $\boldsymbol{c}_{\boldsymbol{c}} \boldsymbol{\$}$ & $\boldsymbol{c}_{\boldsymbol{d}} \boldsymbol{\$}$ & $\boldsymbol{c}_{\boldsymbol{e}} \boldsymbol{}$ & $\boldsymbol{c}_{\boldsymbol{f}} \boldsymbol{\$}$ & $\boldsymbol{C}_{\mathbf{1}}$ \\
\hline 1 & 1 & 4 & 2 & 1 & 3 & 3 & 14 \\
2 & 1 & 4 & 1 & 2 & 4 & 1 & 13 \\
3 & 4 & 6 & 2 & 7 & 3 & 7 & 29 \\
4 & 1 & 6 & 1 & 17 & 2 & 7 & 34 \\
5 & 5 & 1 & 2 & 8 & 2 & 7 & 25 \\
6 & 1 & 5 & 1 & 12 & 4 & 1 & 24 \\
7 & 2 & 6 & 2 & 7 & 2 & 1 & 20 \\
8 & 7 & 3 & 1 & 16 & 1 & 1 & 29 \\
9 & 1 & 1 & 1 & 14 & 4 & 4 & 25 \\
10 & 6 & 1 & 2 & 2 & 4 & 1 & 16 \\
11 & 1 & 1 & 1 & 1 & 4 & 1 & 9 \\
12 & 2 & 5 & 1 & 12 & 3 & 1 & 24 \\
13 & 7 & 2 & 1 & 7 & 3 & 4 & 24 \\
14 & 2 & 5 & 1 & 2 & 3 & 1 & 14 \\
15 & 1 & 1 & 1 & 12 & 2 & 5 & 22 \\
\hline
\end{tabular}

Table A4. Costs for fermentation-based extraction method $(i=2)$.

\begin{tabular}{|c|c|c|c|c|c|c|c|}
\hline Test & $c_{a} \$$ & $c_{b} \$$ & $c_{c} \$$ & $c_{d} \$$ & $c_{e} \$$ & $c_{f} \$$ & $C_{2}$ \\
\hline 1 & 4 & 6 & 1 & 1 & 1 & 4 & 17 \\
\hline 2 & 1 & 5 & 1 & 1 & 3 & 1 & 12 \\
\hline 3 & 1 & 2 & 1 & 1 & 4 & 1 & 10 \\
\hline 4 & 2 & 5 & 1 & 2 & 1 & 3 & 14 \\
\hline 5 & 1 & 3 & 2 & 1 & 1 & 2 & 10 \\
\hline 6 & 5 & 3 & 1 & 2 & 4 & 7 & 22 \\
\hline 7 & 3 & 6 & 1 & 1 & 4 & 4 & 19 \\
\hline 8 & 1 & 4 & 2 & 2 & 1 & 3 & 13 \\
\hline 9 & 5 & 5 & 1 & 2 & 1 & 2 & 16 \\
\hline 10 & 7 & 5 & 1 & 2 & 3 & 3 & 21 \\
\hline 11 & 1 & 1 & 1 & 1 & 1 & 6 & 11 \\
\hline 12 & 6 & 4 & 2 & 1 & 2 & 1 & 16 \\
\hline 13 & 2 & 2 & 1 & 1 & 2 & 1 & 9 \\
\hline 14 & 1 & 1 & 2 & 1 & 3 & 5 & 13 \\
\hline 15 & 4 & 4 & 1 & 1 & 1 & 4 & 15 \\
\hline
\end{tabular}


Table A5. Energy costs for standard extraction method $(i=1)$.

\begin{tabular}{cccccccc}
\hline Test & $\boldsymbol{c}_{\boldsymbol{a}} \boldsymbol{\$}$ & $\boldsymbol{c}_{\boldsymbol{b}} \boldsymbol{\$}$ & $\boldsymbol{c}_{\boldsymbol{c}} \boldsymbol{\$}$ & $\boldsymbol{c}_{\boldsymbol{d}} \boldsymbol{S}$ & $\boldsymbol{c}_{\boldsymbol{e}} \boldsymbol{S}$ & $\boldsymbol{c}_{\boldsymbol{f}} \boldsymbol{\$}$ & $\boldsymbol{E} \boldsymbol{C}_{\boldsymbol{1}}$ \\
\hline 1 & 0.45 & 0.075 & 0.075 & 5.85 & 3 & 0 & 18.15 \\
2 & 0.525 & 0.075 & 0.15 & 29.25 & 3 & 0 & 41.7 \\
3 & 0.45 & 0.075 & 0.075 & 5.85 & 4.5 & 0 & 24 \\
4 & 0.15 & 0.075 & 0.075 & 52.65 & 1.5 & 0 & 58.8 \\
5 & 0.3 & 0.075 & 0.15 & 23.4 & 4.5 & 0 & 41.475 \\
6 & 0.15 & 0.15 & 0.15 & 11.7 & 1.5 & 0 & 18 \\
7 & 0.3 & 0.075 & 0.075 & 5.85 & 4.5 & 0 & 23.85 \\
8 & 0.075 & 0.075 & 0.075 & 5.85 & 4.5 & 0 & 23.625 \\
9 & 0.075 & 0.075 & 0.075 & 64.35 & 3 & 0 & 76.275 \\
10 & 0.375 & 0.075 & 0.15 & 11.7 & 1.5 & 0 & 18.15 \\
11 & 0.3 & 0.075 & 0.15 & 64.35 & 1.5 & 0 & 70.725 \\
12 & 0.075 & 0.075 & 0.075 & 23.4 & 1.5 & 0 & 29.475 \\
13 & 0.3 & 0.15 & 0.075 & 64.35 & 3 & 0 & 76.575 \\
14 & 0.3 & 0.075 & 0.075 & 23.4 & 1.5 & 0 & 29.7 \\
15 & 0.45 & 0.075 & 0.15 & 5.85 & 4.5 & 0 & 24.075 \\
\hline
\end{tabular}

Table A6. Energy costs for fermentation-based extraction method $(i=2)$.

\begin{tabular}{|c|c|c|c|c|c|c|c|}
\hline Test & $c_{a} \$$ & $c_{b} \$$ & $c_{c} \$$ & $c_{d} \$$ & $c_{e} \$$ & $c_{f} \$$ & $E C_{2}$ \\
\hline 1 & 0.3 & 0.075 & 0.15 & 0.15 & 0 & 0 & 2.4 \\
\hline 2 & 0.525 & 0.15 & 0.075 & 0.3 & 0 & 0 & 1.575 \\
\hline 3 & 0.15 & 0.075 & 0.15 & 0.45 & 0 & 0 & 1.875 \\
\hline 4 & 0.3 & 0.075 & 0.075 & 0.075 & 0 & 0 & 1.575 \\
\hline 5 & 0.525 & 0.075 & 0.15 & 0.375 & 0 & 0 & 3.075 \\
\hline 6 & 0.075 & 0.075 & 0.15 & 0.225 & 0 & 0 & 1.05 \\
\hline 7 & 0.45 & 0.075 & 0.075 & 0.15 & 0 & 0 & 1.275 \\
\hline 8 & 0.075 & 0.15 & 0.075 & 0.375 & 0 & 0 & 1.275 \\
\hline 9 & 0.225 & 0.075 & 0.15 & 0.225 & 0 & 0 & 1.8 \\
\hline 10 & 0.525 & 0.15 & 0.075 & 0.075 & 0 & 0 & 1.575 \\
\hline 11 & 0.375 & 0.15 & 0.075 & 0.525 & 0 & 0 & 1.575 \\
\hline 12 & 0.225 & 0.075 & 0.075 & 0.3 & 0 & 0 & 2.025 \\
\hline 13 & 0.3 & 0.075 & 0.075 & 0.3 & 0 & 0 & 1.275 \\
\hline 14 & 0.075 & 0.15 & 0.075 & 0.15 & 0 & 0 & 2.325 \\
\hline 15 & 0.075 & 0.075 & 0.15 & 0.075 & 0 & 0 & 1.35 \\
\hline
\end{tabular}

\section{References}

1. Liu, Y.; Ma, X.; Shu, L.; Hancke, G.P.; Abu-Mahfouz, A.M. From Industry 4.0 to Agriculture 4.0: Current Status, Enabling Technologies, and Research Challenges. IEEE Trans. Ind. Inform. 2021, 17, 4322-4334. [CrossRef]

2. Zhai, Z.; Martínez, J.F.; Beltran, V.; Martínez, N.L. Decision Support Systems For Agriculture 4.0: Survey and Challenges. Comput. Electron. Agric. 2020, 170, 105256. [CrossRef]

3. Casavola, A.; Gagliardi, G. Fault Detection and Isolation of Electrical Induction Motors via LPV Fault Observers. Ifac Proc. Vol. 2012, 45, 800-805. [CrossRef]

4. Nargotra, M.; Khurjekar, M.J. Green house based on IoT and AI for societal benefit. In Proceedings of the 2020 International Conference on Emerging Smart Computing and Informatics (ESCI), Pune, India, 12-14 March 2020.

5. Shadrin, D.; Menshchikov, A.; Somov, A.; Bornemann, G.; Hauslage, J.; Fedorov, M. Enabling Precision Agriculture Through Embedded Sensing with Artificial Intelligence. IEEE Trans. Instrum. Meas. 2020, 69, 4103-4113. [CrossRef]

6. Yang, X.; Shu, L.; Chen, J.; Ferrag, M.A.; Wu, J.; Nurellari, E.; Huang, K. A survey on smart agriculture: Development modes, technologies, and security and privacy challenges. IEEE/CAA J. Autom. Sin. 2020, 8, 273-302. [CrossRef]

7. Gagliardi, G.; Casavola, A.; Lupia, M.; Cario, G.; Tedesco, F.; Lo Scudo, F.; Gaccio, F.C.; Augimeri, A. A smart city adaptive lighting system. In Proceedings of the 3rd International Conference on Fog and Mobile Edge Computing, FMEC 2018, Barcelona, Spain, 23-26 April 2018.

8. Gagliardi, G.; Lupia, M.; Cario, G.; Tedesco, F.; Cicchello Gaccio, F.; Lo Scudo, F.; Casavola, A. Advanced Adaptive Street Lighting Systems for Smart Cities. Smart Cities 2020, 3, 1495-1512. [CrossRef]

9. Bersani, C.; Fossa, M.; Priarone, A.; Sacile, R.; Zero, E. Model Predictive Control versus Traditional Relay Control in a High Energy Efficiency Greenhouse. Energies 2021, 14, 3353. [CrossRef]

10. Ferrandez-Pastor, F.J.; Garcia-Chamizo, J.M.; Nieto-Hidalgo, M.; Mora-Pascual, J.; Mora-Martinez, J. Developing ubiquitous sensor network platform using Internet of Things: Application in precision agriculture. Sensors 2016, 16, 1141. [CrossRef] [PubMed]

11. Wolfert, S.; Ge, L.; Verdouw, C.; Bogaardt, M.J. Big data in smart farming-A review. Agric. Syst. 2017, 153, 69-80. [CrossRef]

12. Liakos, K.G.; Busato, P.; Moshou, D.; Pearson, S.; Bochtis, D. Machine learning in agriculture: A review. Sensors 2018, 18, 2674. [CrossRef] [PubMed] 
13. Gagliardi, G.; Lupia, M.; Cario, G.; Cicchello Gaccio, F.; D’Angelo, V.; Cosma, A.I.M.; Casavola, A. An Internet of Things Solution for Smart Agriculture. Agronomy 2021, 11, 2140. [CrossRef]

14. Taechatanasat, P.; Armstrong, L. Decision support system data for farmer decision making. In Proceedings of the Asian Federation for Information Technology in Agriculture, Perth, Australian, 29 September-2 October 2014; Australian Society of Information and Communication Technologies in Agriculture, pp. 472-486. Available online: https://ro.ecu.edu.au/ecuworkspost2013/855/ (accessed on 27 December 2021).

15. Tyrychtr, J.; Vostrovsky, V. The current state of the issue of information needs and dispositions among small Czech farms. Agric. Econ. 2017, 63, 164-174. [CrossRef]

16. Bazzani, G.M. An integrated decision support system for irrigation and water policy design: DSIRR. Environ. Model Softw. 2005, 20, 153-163. [CrossRef]

17. Anderl, R. Industrie 4.0-Technological approaches, use cases, and implementation. AT Autom. 2015, 63, 753-765. [CrossRef]

18. Improving Energy Efficiency in the Agro-Food Chain. Available online: https://www.oecd.org/officialdocuments/ publicdisplaydocumentpdf/?cote=COM/TAD/CA/ENV/EPOC(2016)19/FINAL\&docLanguage=En (accessed on 27 December 2021).

19. Keefer, D.; Kahkonan, S. Perspective on decision analysis applications. Decis. Anal. 2004, 1, 5-24. [CrossRef]

20. Barnes, R.; Ashbolt, N. Review of Decision Tools and Trends for Water and Sanitation Development Projects. In Proceedings of the 32nd WEDC International Conference, Colombo, Sri Lanka, 13-17 November 2006; pp. 187-194.

21. Churchill, C.J.; Baetz, B.W. Development of decision Support Systmes for Sustainable Community Design. J. Urban Plan. Dev. 1999, 125, 17-35. [CrossRef]

22. Walsh, M.R. Toward Spatial Decision support Systems in Water Resources. J. Water Resour. Plan. Manag. 1993, 119, 158-169. [CrossRef]

23. Turban, E.; Aronson, J.E.; Bolloju, N. Decision Support Systems and Intelligent Systems; Prentice Hall International: Upper Saddle River, NJ, USA, 2005.

24. Marakas, G.M. Decision Support Systems in the Twenty-First Century; Prentice Hall: Upper Saddle River, NJ, USA; London, UK, 2003.

25. Morge, M.; Mancarella, P. The Hedgehog and the Fox: An Argumentation based Decision Support System. Lect. Notes Comput. Sci. 2008, 4946, 114-131.

26. Wallace, T.C. Health Effects of Coconut Oil-A Narrative Review of Current Evidence. J. Am. Coll. Nutr. 2019, 38, 97-107. [CrossRef] [PubMed]

27. Odigboh, E.U. Machines for Crop Production. In CIGR Hand-Book of Agricultural Engineering; Stout, B.A., Ed.; American Society of Agricultural Engineers: St Joseph, MI, USA, 1998; Volume III.

28. Bamgboye, A.I.; Jekayinfa, S. Energy consumption pattern in palm kernel processing operations. J. Appl. Sci. Eng. Technol. 2004, 4, 26-31. [CrossRef] 